\title{
Breakdown of the ideal free distribution under conditions of severe and low competition
}

\author{
Janja Sirovnik $^{1,2}$ (D) $\cdot$ Bernhard Voelk| $^{3} \cdot$ Linda Jane Keeling $^{4} \cdot$ Hanno Würbel $^{1,3} \cdot$ Michael Jeffrey Toscano $^{1}$
}

Received: 5 February 2020 / Revised: 4 December 2020 / Accepted: 10 December 2020 / Published online: 19 January 2021

(C) The Author(s) 2021

\begin{abstract}
Under the ideal free distribution (IFD), the number of organisms competing for a resource at different sites is proportional to the resource distribution among sites. The ideal free distribution of competitors in a heterogeneous environment often predicts habitat matching, where the relative number of individuals using any two patches matches the relative availability of resources in those same two patches. If a resource is scarce, access might be restricted to individuals with high resource holding potential, resulting in deviation from the IFD. The distribution of animals may also deviate from the IFD in the case of resource abundance, when social attraction or preference for specific locations rather than competition may determine distribution. While it was originally developed to explain habitat choice, we apply the habitat matching rule to microscale foraging decisions. We show that chickens feeding from two nondepleting feeders distribute proportionally to feeder space under intermediate levels of competition. However, chicken distribution between the feeders deviates from the IFD when feeder space is limited and competition high. Further, despite decreasing aggression with increasing feeder space, deviation from IFD is also observed under an excess supply of feeder space, indicating different mechanisms responsible for deviations from the IFD. Besides demonstrating IFD sensitivity to competition, these findings highlight IFD's potential as a biological basis for determining minimal resource requirements in animal housing.
\end{abstract}

\section{Significance statement}

The ideal free distribution (IFD) predicts how animals ought to distribute themselves within a habitat in order to maximize their payoff. Recent studies, however, have questioned the validity of the IFD concept following anomalous results. We studied the IFD in chickens by systematically varying the amount and distribution of space at two feed troughs. We show that when tested over a sufficiently large range, the distribution of birds depends on the overall resource availability. Furthermore, behavioral data suggest that distinctly different mechanisms account for deviations from the IFD at shortage and excess supply of feeder space, respectively.

Keywords Laying hens $\cdot$ Feeder space $\cdot$ Matching rule $\cdot$ Social attraction $\cdot$ Aggression

Communicated by S. Pruett-Jones

Janja Sirovnik

janja.sirovnik-koscica@vetmeduni.ac.at

1 Center for Proper Housing: Poultry and Rabbits (ZTHZ), Division of Animal Welfare, VPH-Institute, University of Bern, Burgerweg 22, 3052 Zollikofen, Switzerland

2 Institute of Animal Welfare Science, University of Veterinary Medicine, Veterinaerplatz 1, 1210 Vienna, Austria

3 Division of Animal Welfare, VPH-Institute, University of Bern, Längassstrasse 120, 3012 Bern, Switzerland

4 Department of Animal Environment and Health, Swedish University of Agricultural Sciences, Box 7068, 75007 Uppsala, SE, Sweden

\section{Introduction}

The ideal free distribution (IFD) is the prediction of an optimization model describing how individuals of a species should distribute in a heterogeneous environment in order to maximize fitness (Fretwell and Lucas 1969). As direct fitness estimates are usually unavailable, resource acquisition is commonly used as a proxy (Parker and Stuart 1976). Originally phrased as a habitat choice model, it was later generalized and applied to different spatial and temporal scales, including various choice situations - though most notably foraging decisions (Milinski 1979; Abrahams 1986; Kennedy and Gray 1993; Koops and Abrahams 1999). Game theoretical work shows that the IFD is 
an evolutionary stable strategy (Křivan et al. 2008) and field studies demonstrated that animals often distribute according to model predictions (e.g., Haugen et al. 2006; Munubi et al. 2018).

Since its initial conceptualization, the IFD has been tested across a wide variety of contexts. These include habitat use in a natural environment and/or resource abundance in relation to animal fitness (Beckmann and Berger 2003), plant root competition for nutrients (McNickle and Brown 2014), insect distribution and disease transmission (Kelly and Thompson 2000), migrations and settlements for human populations (Jazwa et al. 2013; Giovas and Fitzpatrick 2014), and land/ water use by farmers/fishers (Abernethy et al. 2007; Moritz et al. 2014). The concept also contributes to our understanding of contemporary problems such as habitat destruction, climate change, and the relationship of such problems to resource distribution. For example, the IFD can help predict the distribution of animals, thereby facilitating conservation and wildlife management (Kennedy and Gray 1993).

According to the matching rule (Parker 1978; Tregenza 1995), if the IFD is to be established, the number of competitors in a patch should be proportional to the total amount of resource in the patch. The basic IFD model for the matching rule assumes that all animals have (1) information about the quality of resources in all patches, (2) information about the distribution of competitors, (3) free ability to choose the resource, and (4) equal competitive abilities (Houston and McNamara 1988; Milinski 1994; Hakoyama 2003). Sutherland (1983) proposed an extension of the basic model specifically for the case of non-depleting resources, i.e., patches where items are arriving continuously. For instance, in many environments, animals search patches for dispersed food items (normally prey), which remain at roughly constant density. In these situations, intake rate is constant and limited by search and processing time (Tregenza 1995). However, social interference of coforaging conspecifics can reduce foraging efficiency. Thus, even if food is available in abundance, accessibility can become a critical and density dependent parameter (Parker and Sutherland 1986; Done et al. 1996).

The IFD was initially investigated by manipulating the quality of resources and measuring the distribution of animals between the resource locations. Those studies revealed possible limiting factors of the IFD, e.g., unequal competitor abilities, predation risk, travel distance, insufficient information, and competition between species (Abrahams 1986; Gillis and Kramer 1987; Korona 1990; Cressman et al. 2004; Berec et al. 2006; Maszczyk et al. 2018; Menezes and Kotler 2019). The IFD may also depend on the level of competition among animals, as demonstrated by manipulating the total amount of resource (resource input) and/or competitor density (Gillis and Kramer 1987; Tregenza et al. 1996). Thus, the greater the competition, the more the distribution deviated from the IFD
(Gillis and Kramer 1987; Tregenza et al. 1996). For instance, in fish, aggressive individuals have been observed to influence distribution by excluding subordinate conspecifics from a superior resource (Church and Grant 2019). In chickens, competition for resources is indicated by increased aggression and jostling (Sirovnik et al. 2018) and might influence bird distribution (Hakoyama and Iguchi 2001). Further, gathering sufficient information about resource quality is one of the most important prerequisites for establishing the IFD (Milinski 1984; Abrahams 1989; Korona 1990). Animals may be sensitive to competitor densities, competitor activities, and/or levels of aggression at each resource location. Information can be gathered by sampling (e.g., individuals move between the resources) or observing from a distance. Thus, recording animal movements between resources might be beneficial for interpreting animal distribution.

In the present study, which is of an explorative character, we studied how groups of laying hens distribute themselves between two feeders in response to variations in total feeder space and resource ratio. We expected that chickens would distribute themselves according to the matching rule at some feeder spaces, while under conditions of both small and large total feeder space chicken distribution might not correspond to the matching rule. For example, when feeder space is abundant, social attraction may determine distribution as chickens are known for their preference to eat from the same food source (Mills and Faure 1989) as well as for their social attraction even when not feeding (Febrer et al. 2006). Birds might prefer to flock to lower the risk of predation due to dilution of risk, confusion effect, or increased vigilance (Milinski and Heller 1978; Lima and Dill 1990; Murali et al. 2019)). Further, at abundant feeder space, when birds do not need to compete for the feeding resource, their preference for specific locations might affect distribution. On the other hand, when feeder space is scarce, competition for access to the feeder might outweigh other types of motivation. Although not the case in all species and all cases of increased competitor-to-resource ratios (Grant et al. 2000), chickens show increased aggression and jostling when feeding resources are scarce (i.e., 4-6 cm feeding space per bird; Sirovnik et al. 2018). Hence, when feeder space is scarce and does not allow for simultaneous feeding, increased aggression (Sirovnik et al. 2018) together with unequal competitive abilities among the chickens (Banks et al. 1979) might lead to deviations from the IFD. For this reason, additionally to the chicken distribution, we also measured levels of aggression and jostling at the feeders. Tracking animal movements between the feeding sites is necessary to understand the mechanisms involved in the distribution of animals between the feeding sources. We predicted that animals would switch from the overpopulated to the less populated feeding site (i.e., to achieve IFD) or move from the feeder with increased aggression to the feeding site with less aggression. 
In order to explore relationships between absolute and relative resource availability and chicken distribution, we included a test condition, where feeder space was clearly insufficient to allow all hens to feed simultaneously $(4 \mathrm{~cm} / \mathrm{hen})$ and other conditions where feeder space was larger than required for simultaneous feeding (18 and $27 \mathrm{~cm} / \mathrm{hen}$ ) as well as intermediate feeder space allocations ( 8 and $10 \mathrm{~cm} / \mathrm{hen}$ ). A secondary aim of this study was to investigate whether the IFD could serve as a yardstick to specify minimum feeding space requirements for group housed animals.

\section{Material and methods}

\section{Animals and housing}

Chickens (Gallus domesticus, Lohmann Selected Leghorn, $N$ =620) were brought to the Aviforum experimental facility (Zollikofen, $\mathrm{CH}$ ) when 1-day old. Initially, chicks were kept in a single large group, but were haphazardly allocated to five pens at 5 weeks of age, and to 10 pens at 10 weeks of age, all within the same barn. At 18 weeks of age, we weighed all birds and examined their appearance (i.e., the condition of the feather coverage as well as the development and shape of the comb, beak, and feet). Chickens of a similar weight and with a well-developed and healthy appearance were used in the study. In total, 200 chickens housed in 10 identical pens, i.e., 20 chickens per pen, were used in this experiment. The experiment began when the chickens reached 19 weeks of age and lasted for 20 weeks. Management practices such as feeding and lighting schedules followed standard commercial practices and were applied uniformly to all pens unless stated otherwise.

Birds wore a pen-specific leg band and were individually marked with a silicone backpack, consisting of two silicone squares (each square: $7 \mathrm{~cm} \times 6 \mathrm{~cm} \times 0.4 \mathrm{~cm} ; 35 \mathrm{~g}$ ) that sat on the back of the bird, and two soft and flexible, plastic clothline-wires that looped around the wings and were attached to the squares through eyelets (Harlander-Matauschek et al. 2009). Each backpack was assigned one of 20 color combinations to allow identification of individual hens in that pen (using the colors green, yellow, red, white, and blue).

All pens $(2.53 \times 2.03 \times 4.33 \mathrm{~m})$ were identical and equipped with two parallel feeders, perches, a drinker, and a nest box positioned in the middle of the pen (Fig. 1). Pens were arranged in two rows. Each pen contained two lamps providing artificial light (average light intensity at feeders was six Lux) mounted on the wall above each feeder. No natural light was provided. Feed was constantly available from $2 \mathrm{~min}$ before the lights came on (dawn) until $30 \mathrm{~min}$ before the lights went off (dusk). Feed was provided by a commercial poultry feed conveyor, which ran through all pens in a row on one side first and back to the motor on the other side of the pens (orange arrows in Fig. 1). Every $2-3 \mathrm{~h}$, the conveyor belt was switched on for $3 \mathrm{~min}$ and $40 \mathrm{~s}$ to replenish all feeders. The feeders were accessible from both sides, and birds were free to choose between feeders.

\section{Experimental design}

During the experiment, total feeder space and the ratio of the space at the two feeders (henceforth "resource ratio") were systematically varied in each pen while bird density in the pen stayed constant. This was done by covering different proportional sections of each of the two lines of the feeders so that pen-specific feeder space was provided in different ratios (resource ratio), and a single continuous section of each feeding site was accessible for feeding. As the amount of feed in the feeders did not diminish perceivably during the observation windows, it can be considered a continuous supply. Given that the feeders constantly provided unlimited feed, the design in our study had the same properties as the continuous-input model where it was not feed, as such, but access to the feeder that was the critical resource influencing bird distribution.

Feeder space is defined as total length of the feeder per hen: $2 \times(L+S) / N$, where $L$ is length in $\mathrm{cm}$ of the larger feeder available for feeding, $S$ is the length in $\mathrm{cm}$ of the smaller feeder available for feeding, and $N$ is the number of hens in the pen. Multiplying the total length by two was done to reflect that a hen could access the feeder from either side, a calculation commonly used in legislation for determining how many chickens can be housed within a facility (The Council of the European Union 1999; The Swiss Federal Council 2008). Five feeder space allocations were used with $4,8,10,18$, or $27 \mathrm{~cm}$ of feeder space per bird. The range of used feeder spaces was based on recommendations for North American producers ( $4 \mathrm{~cm} / \mathrm{hen}$ (United Egg Producers 2016)), Swiss $(8 \mathrm{~cm} / \mathrm{hen}$ (The Swiss Federal Council 2008)), and European legislations $(10 \mathrm{~cm} / \mathrm{hen}$ (The Council of the European Union 1999)). The abundant feeder space allocations were based on giving slightly more than the average and double the average width of an adult Lohmann Selected Leghorn chicken torso (13.4 cm (Briese and Spindler 2013)), i.e., providing $18 \mathrm{~cm} / \mathrm{hen}$ and $27 \mathrm{~cm} / \mathrm{hen}$ feeder space.

Resource ratio is defined as $L / S$. For each feeder space, we provided 40 different ratios ranging from 1:1 to $1: 10.75$. Feeder space and resource ratio were changed weekly in each pen. The experiment was counterbalanced in a manner that the provision of feeder spaces and resource ratios were randomized over the whole experiment ( 20 weeks) with the following restrictions: each feeder space was presented in two pens each week, each feeder space was used four-times per pen, and the larger feeder space allocation was equally distributed between both pen sides (see supplementary Table S1). We used 10 pens with a weekly change in the feeder space and resource 
Fig. 1 Visual representation of the barn, feed troughs, and pen setup with measurements. All pens had the same arrangement as pen 1 and 2 in this figure. Feed troughs are represented with orange lines, feed motors with orange squares, a drinker with a blue circle, the nest box with a grey square, and a ventilation tube with a grey circle. The floor was covered with wood shavings (yellow shaded area)

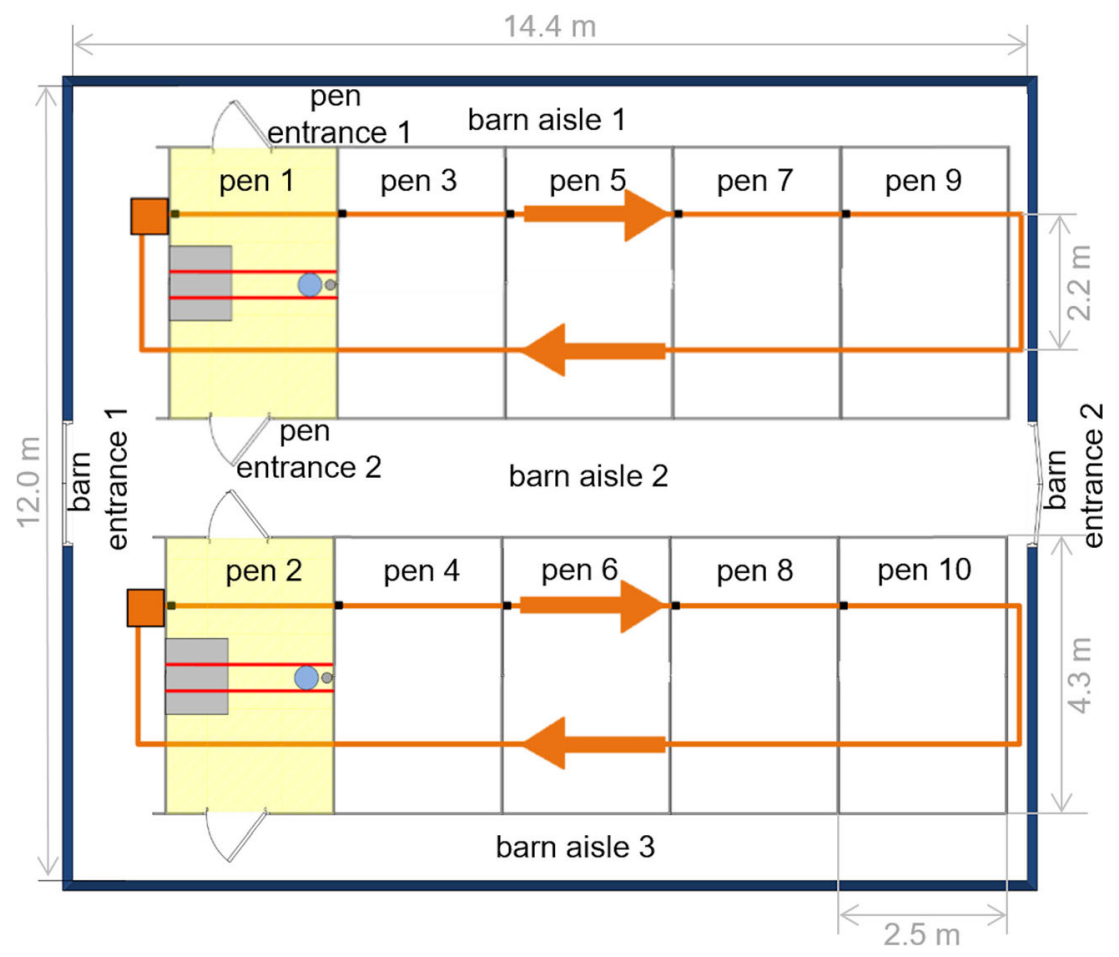

ratio for a total of 20 weeks. However, due to issues with the birds not being able to access both feeding sites at some resource ratios at $4 \mathrm{~cm} /$ hen feeder space as well as due to feed delivery problems in four pens in the first 6 weeks of the experiment, we could not use all data for the analysis. Thus, the sample size $(\mathrm{N})$ corresponds to 167 replicates on the group level.

\section{Data collection}

Two days after adjusting feeder space and resource ratios, hen behavior at the feeder was video recorded using a camera fitted to the ceiling for a 30 -min period on five consecutive days, but only a subset of the video material was used for detailed analysis. Videos on day 5 were used for behavioral coding, except in cases where the recording could not be used due to technical problems with a camera, whereupon recordings on day four were used (this was the case on five occasions). Videos from the other days were used to check whether feed delivery worked properly.

A preliminary analysis (supplementary material) showed that within the 30 -min video recording the majority of chickens were simultaneously at the feeder 6-7 min after the light came on (8-9 min after delivery of the feed). Hence, a 3-min interval (observation period) lasting from 5 to 8 min after the lights came on was included in the analysis of behavior. The observer (JS) was not aware of the exact feeder space, resource ratio, or age, though it was not possible to completely blind the observer as the whole length of the feeder was visible.
The presence and position of each hen at the feeder was identified in the 3-min observation period at each 30-s-time step (i.e., the observation period was divided into seven sample points). The possible positions were (1) at the larger feeder, (2) at the smaller feeder, and (3) not at either of the feeders. From these data, we extracted: hen distribution between the resources, number of birds at the resource at the same time (simultaneous feeding), competitor density, switching between resources and transitions from being at the resource or away from it. Switching was defined as a hen leaving one feeder and arriving at the other feeder in the next sample point and a transition as a hen leaving the feeder to go elsewhere in the pen (not to the other feeder) or, from being elsewhere, coming to a feeder. From the length of the feeders and number of chickens at the feeders, we calculated competitor densities at both feeders in the pen before and after a bird switched from one resource to another.

Behaviors of interest were aggression and jostling. An act was characterized as aggression (point event) when a hen pecked or chased another hen (feather manipulation was not considered as aggression). Jostling (point event) was defined as an act where a hen pushed her body between, under, or above other hens at the feeder. An actor was a bird that was actively initiating the behavior and a receiver was passively involved in jostling or the target of aggression. The actors' behavior preceding jostling was used to further classify jostling followed by a behavior other than feeding as (1) leave the feeder, or (2) other, e.g., walking between the feeding birds to access another type of resource. As a result of a jostling event, the receiver could 
either (1) stop feeding and leave the feeder (interrupted feeding) or (2) continue feeding.

\section{Statistical analysis}

For statistical analysis, we used the statistical software R ( R version 3.2.2. (R Core Team 2016)) employing general and generalized linear mixed models (using packages 'Ime4' (Bates et al. 2015) and lmerTest (Kuznetsova et al. 2016)). If not stated otherwise, predictors were feeder space, resource ratio, age, pen side of the larger resource, and the feeder space $\times$ resource ratio and feeder space $\times$ age interactions. Pen was considered as a random factor. The fit of each model was examined using Q-Q plots of the residuals and plots of predicted versus fitted values. All model outputs supporting this article have been uploaded as part of the supplementary material (see Figure S1 and Tables S2-S5).

To describe bird distribution at the feeders with respect to resource availability, we first calculated the ratio of resources where the numerator was the length of the larger resource $(\mathrm{cm})$ and the denominator the length of the smaller resource $(\mathrm{cm})$. When the resource ratio was $1: 1$, both pen sides were equally often designated as a numerator and denominator. For the analysis, we used a logarithmic transformation $\left(\log _{10}(\mathrm{x})\right)$ of the resource and competitor ratios. To assess the relationship between the distribution of the chickens across the two feeders and resource ratio for each feeder space allocation, we fitted linear mixed effect regression models with Gaussian error terms for each feeder space. The model included the logtransformed ratios of the number of birds at the resource locations (as the response variable), the log-transformed resource ratios as a predictor variable, age as a covariate, and pen as a random factor. The logarithmic transformation of the ratios takes care of the expected heteroscedasticity of ratios of small numbers. Under the IFD, one expects a linear relationship between the log-ratio of the number of birds at the resources and the log-ratio of resource availability with an intercept of zero and a slope of one. In order to construct confidence intervals for the expected slope, we used simulated resampling, where for each trial and each time point, we randomly reallocated hens to feeders with probabilities proportional to the resource ratio and fitted a regression line through the origin to the simulated data. This procedure was repeated 5000 times and the upper and lower 2.5 percentiles were taken as nonparametric confidence intervals.

In addition to the primary analysis of the distribution of animals in response to resource abundance and resource ratio, we performed several exploratory analyses focusing on the choice behavior and social interactions (aggression and displacement) of the animals. For this purpose, several inferential tests were made. Predictors were considered significant at $p<$ 0.05 , however, as this part of the study had an exploratory character and multiple statistical models $(k=8)$ were tested, we recommend interpreting $p$ values against a Bonferroni corrected threshold level of $\alpha^{\prime}=0.006$.

Transitions were analyzed with a GLMM assuming a Poisson distribution and using restricted maximum likelihood (REML) estimation. Switching between feeders was analyzed with a GLMM and treated as a binomial response with a hen either changing position between feeders or staying at one feeder during the observation period. For the analysis of transitions and switches, we included feeder space, resource ratio, age, and pen side of the larger resource as fixed factors and pen as a random factor (i.e., no interactions used).

We also tested whether competitor density at the feeders affected switches between the feeders. The feeder where a hen was seen at the last observation point before the switch is referred to as the resource of origin and the feeder where it was seen at the first observation point after the switch as the target resource. For each feeder space condition, we ran three chisquared tests: (1) bird density at the resource of origin before the switch (density origin before) $\sim$ bird density at the target resource before the switch (density target before), (2) density origin before $\sim$ density target after the switch (density target after), (3) density origin after the switch (density origin after) $\sim$ density target after. The $x^{2}$ values for the five feeder space allocations were then used to calculate combined probabilities (Sokal and Rohlf 1995). To identify whether switches between the feeders were related to the number of birds at the feeders, we ran one additional chi-squared test for each feeder space condition, adjusting expected values for switches by the total numbers of birds at the feeders. For the average number of competitors and number of different competitors, we assumed a Poisson distribution and used a log link function in two separate GLMMs for analysis. The prevalence of aggression at both resources in a pen was analyzed with a GLMM assuming a Poisson distribution. To test whether the prevalence of aggression was increased at the larger resource, a separate GLMM including aggression as a binomial response variable was performed. The prevalence of jostling followed by feeding at both resources in the pen was analyzed with a GLMM assuming a Poisson distribution. The incidences of interrupted feeding following jostling at both resources were analyzed with a GLMM with an assumed Poisson distribution.

\section{Results}

\section{Bird distribution between feeders}

Under the ideal free distribution we expect that birds distribute proportional to the available feeder space, so that a regression of the $\log$ hen ratio against the log feeder space ratio should be a straight line with intercept $=0$ and slope $=1$. The observed slopes increased from 0.84 for $4 \mathrm{~cm} /$ bird of feeder space to 1.10 and 1.09 for $8 \mathrm{~cm} /$ bird and $10 \mathrm{~cm} / \mathrm{bird}$, respectively, and 
then decreased to 0.81 for $18 \mathrm{~cm} /$ bird and 0.70 for $27 \mathrm{~cm} /$ bird (Figs. 2, 3a). Thus, while for feeder spaces of 4,18 , and 27 $\mathrm{cm} /$ hen, we see significant deviations from the IFD (slope $=1$ ) at the $5 \%$ level, when birds are offered 8 and $10 \mathrm{~cm} /$ hen feeder space, the observed slopes fall squarely into the range of expected slopes under IFD. Bird distribution at the feeder was not associated with age $(p=0.919)$.

\section{Number of birds, amount of switching between resources, and transitions from being at the feeder or away from it}

On average, $14.9 \pm 2.5$ (mean $\pm \mathrm{SD}$ ) out of 20 individuals accessed one or both feeders (resources) in a pen during the 3 -minute observation period. On average, $6.9 \pm 2.4$ birds were at the feeders simultaneously (overall average, irrespective of feeder space, resource ratio, age, and pen side).

The number of different individuals at the feeder within the observation period was independent of feeder space, resource ratio, or pen side ( $p=0.819,0.323$, and 0.426 , respectively; Table S1) but decreased with age $(p=0.0004)$. The number of birds simultaneously at the feeder increased with increasing feeder space ( $p=0.006$; Fig. $3 \mathrm{~b}$ ) mainly due to an increase from 4 to $8 \mathrm{~cm} / \mathrm{bird}$, since there was almost no increase in the number of birds simultaneously at the feeder when more than $8 \mathrm{~cm} / \mathrm{bird}$ of feeder space was provided. The number of birds simultaneously at the feeder decreased with increasing resource ratio $(p=0.004)$ and age $(p=0.0004)$. The side of the pen where the larger resource was located had no effect on bird distribution $(p=0.695)$.

When a bird either approached or left the feeder, the event was classified as a "transition". Over the course of the study, we recorded 7185 transitions (overall mean \pm SD: $0.7 \pm 0.5$ transitions $/ \mathrm{min} /$ bird). We found no relationship between transitions and feeder space $(p=0.850)$ or pen side $(p=0.709)$. However, transitions decreased with larger resource ratios $(p<0.0001)$ and with increasing age $(p<0.0001$; Table S2). When a bird left one feeder and arrived at the other feeder shortly afterwards, i.e., within the observation period, this was referred to as "switching". Over the course of the study, switching occurred 537-times (mean \pm SD: $0.05 \pm 0.1$ switches $/ \mathrm{min} /$ bird). We found no relationship between switching and feeder space ( $p=0.373$ ), but switching occurred less often at larger resource ratios $(p<0.0001)$ and as birds got

Fig. 2 Best fitted lines (red line), 95\% confidence intervals (grey shading), 99\% confidence intervals (blue shading), and raw data points of the relationships between log competitor ratio on the y-axis and log resource ratio on the $x$-axis for each of feeder spaces. Dashed lines represent the expectation of the ideal free distribution and dots represent pens. Best-fitted lines are based on the generalized linear models without random factors $(n=167)$
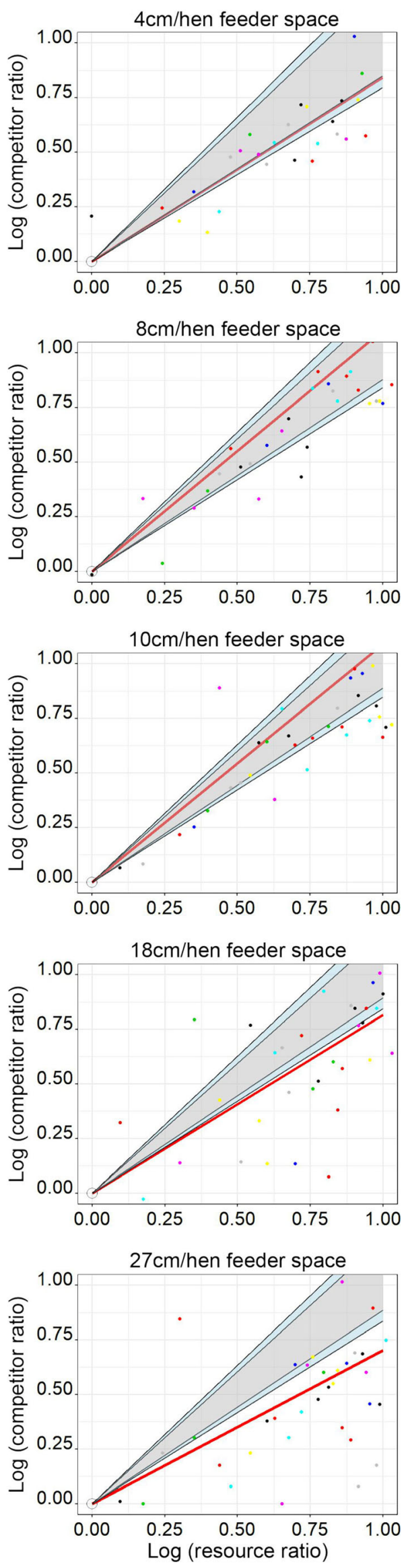

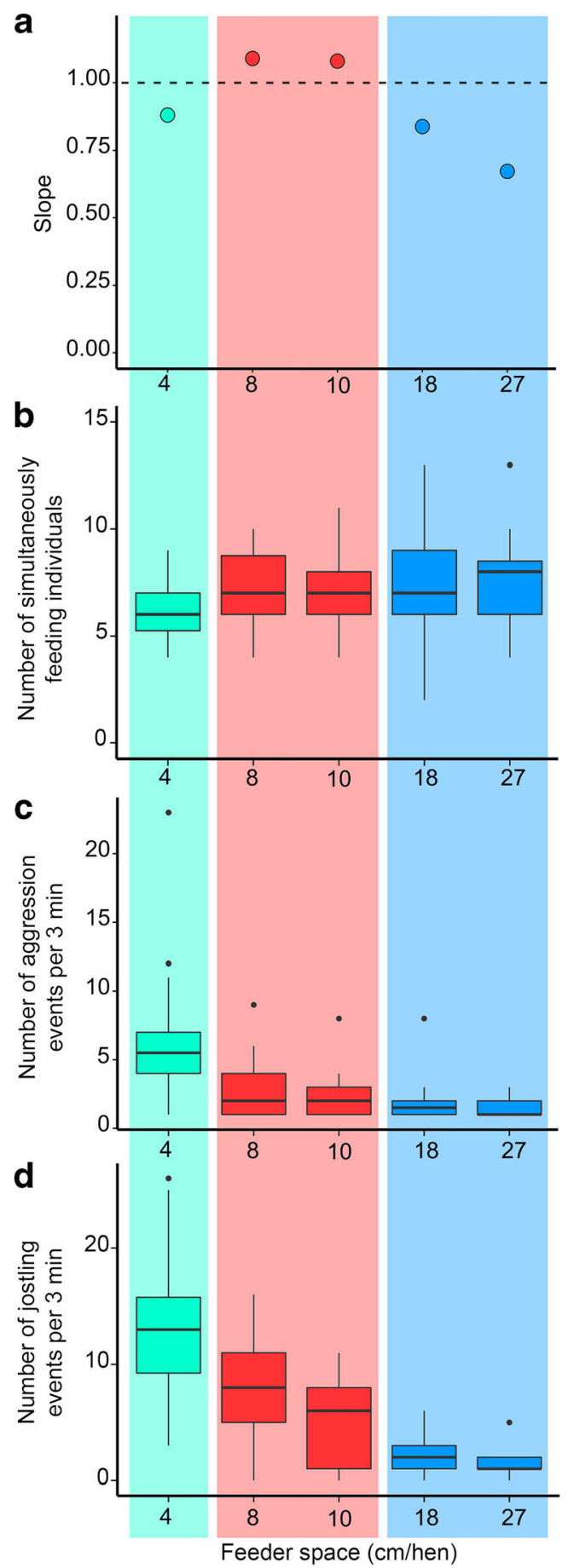

Fig. 3 Relationship of the primary response variables (a slope of regression models of competitor ratio $(\log )$ and resource ratio $(\log ), \mathbf{b}$ number of simultaneously feeding individuals, $\mathbf{c}$ number of aggression events, $\mathbf{d}$ number of jostling events) and feeder space. Red shading shows feeder spaces where the distribution was close to ideal, green and blue shadings show feeder spaces with deviations from ideal free distribution, but with different effects on behavior. b-d Box-and-Whiskers plots, boxes $=1 s t$ and $3 r d$ quartile, thick line $=$ median, whiskers $=$ range of data (within $1.5 \times$ interquartile range), dots $=$ outliers (data points outside $1.5 \times$ interquartile range; $n=167$ )

older $(p<0.0001)$. Switching was not affected by the pen side of the larger resource $(p=0.433)$.
For switching between feeders, we examined whether the bird density at the original feeder (from which the bird moved away) was larger or smaller than at the target feeder (to which the bird moved). Before switching, the density at the original feeder was higher than at the target feeder for all five feeder spaces (Table 1, Fig. 4a). After switching, the density was consistently higher at the target feeder than it was now at the original feeder (Fig. 4b). The bird density at the target feeder after switching did not differ from the bird density at the original feeder before switching ( $p=0.923$; Fig. $4 \mathrm{c})$. This means that birds switching feeders predominantly moved when the density at the target was lower than at the origin ("moving away from the crowd"). However, due to the movement, the relation reversed and after switching the density at the target was higher than at the origin. As a result, the birds that moved from one source to another did not experience a change in density at the feeder, while those that stayed behind experienced a decrease in bird density at the feeder. This effect remains significant when we adjust expected values for switches by the total numbers of birds present at the feeders (Table 1).

\section{Competition at the feeder}

Aggression (an aggressive peck at the head or body of another bird or chasing another chicken) and jostling (a bird pushing her body between, under, or above the feeding birds) were observed in total 323 times $(0.644$ times $/ \mathrm{min} / \mathrm{pen})$ and 877 times (1.750 times/min/pen), respectively. Overall, there was a strong decrease in aggression with greater feeder space ( $p<0.0001$; Fig. 3c), though an interaction existed between feeder space and resource ratio for aggression ( $p=$ 0.001; Table S3). Thus, aggression was independent of the resource ratio at $4 \mathrm{~cm} /$ bird feeder space while at other feeder spaces, aggression increased with increasing resource ratios ( $p=0.001$; Fig. S1). Additionally, an interaction of feeder space and age was found for aggression $(p=0.007)$, indicating that aggression decreased with age at feeder spaces of 4 and $8 \mathrm{~cm} / \mathrm{hen}$, while aggression was not related to age for other feeder spaces (Fig. S1b). Pen side of the larger resource did not affect aggression $(p=0.986)$. The prevalence of aggression did not differ between the small and large feeder within the same pen, regardless of feeder space $(p=0.828)$, resource ratio $(p=0.456$; Table S3), age $(p=0.64)$, or pen side of the larger resource $(p=0.284)$. Birds were jostling less with increasing feeder space $(p<$ 0.0001; Fig. 3d, S2, Table S4), and older birds jostled less than the younger $(p=0.001)$. Jostling was not associated with resource ratio $(p=0.36)$ or pen side of the larger resource $(p=0.273)$. Interrupted feeding (after a jostling event a target bird stopped feeding and left the feeder) was more frequent at smaller feeder space $(p<0.001$; Fig. 5, Table S5), but interrupted feeding did not relate to resource 
Table $1 x^{2}$ values for switching from the original feeder (from which the bird moved away) to the target feeder (to which the bird moved) depending on bird density. For the comparison of switches "Origin-
Before" vs. "Target-Before" additional chi-squared values based on expected values adjusted for the total numbers of birds present at the feeders are presented in the brackets

\begin{tabular}{llll}
\hline Feeder space $(\mathrm{cm} / \mathrm{hen})$ & Origin Before $<$ Target Before & Origin After $<$ Target After & Origin Before $=$ Target After \\
\hline 4 & $5.88(2.72)$ & 4.26 & 0.21 \\
8 & $1.74(2.29)$ & 7.19 & 0.00 \\
10 & $3.45(2.14)$ & 7.35 & 0.27 \\
18 & $11.71(7.33)$ & 3.88 & 0.27 \\
27 & $8.98(6.16)$ & 0.94 & 0.16 \\
overall & $x^{2}=31.76, \mathrm{df}=5, p<0.001$ & $x^{2}=23.63, \mathrm{df}=5, p=<0.001$ & $x^{2}=0.91, \mathrm{df}=5, p=0.969$ \\
& $\left(x^{2}=20.64, \mathrm{df}=5, p<0.001\right)$ & & \\
\hline
\end{tabular}

ratio $(p=0.874)$, age $(p=0.715)$, or pen side of the larger resource $(p=0.443)$.

\section{Discussion}

We studied IFD in the context of feeder space, which determined chicken's access to the feed. In this context "choice" is the choice of one of two feed troughs in one pen, while payoff is measured in terms of access to feed. Weekly modifications of feeder space and resource ratio allowed us to generalize the results over different situations, and the results indicated that chickens adapted to the changing conditions. We found that under unlimited food availability, there are certain feeder space allocations that lead to a distribution of hens as predicted by the matching rule. We suggest that this feeder space can be interpreted as providing sufficient access to the resource.

Providing not only one, but several levels of overall space availability at the resource allowed us to establish a response of expected matching proportions. Doing so, we found proportionate settlement between the resources for a narrow range of space availability, while at both extremes of space availability at the feeders (equivalent to scarcity and abundance of the resource) undermatching is observed. The derived prediction curve lets us view the accumulated work on animal distributions in a new light. Undermatching of animals and resource availability has often been interpreted as a failure of the IFD model and, according to Bradbury et al. (2015), the consistent failure of finding close proportionate settlement was the main reason why interest in the IFD models waned over the last decades. Here, we provide evidence by example that abandoning the idea of the IFD because undermatching is observed for a specific level of resource abundance might be premature. If prediction curves, as we found in our study, are widely applicable then the pattern of frequent observations of undermatching, few cases of matching, and rare cases of overmatching (as reported by Zach and Smith 1981; Abrahams 1986; Kennedy and Gray 1993; Bautista et al. 1995; Tregenza 1995), is exactly what should be expected. Notably, undermatching of animal distribution with resource distribution does not contradict the basic tenet of the IFD theorem that individuals should distribute in a manner to maximize fitness. If fitness would always scale linearly with the access to feed, we should expect proportionate settlement under all conditions of resource abundance and resource distribution; this is unlikely to be the case. There will be ceiling effects, where even higher abundance of food cannot increase fitness anymore, and resource availability might not be the only factor affecting fitness. Furthermore, relative and absolute group sizes at resource
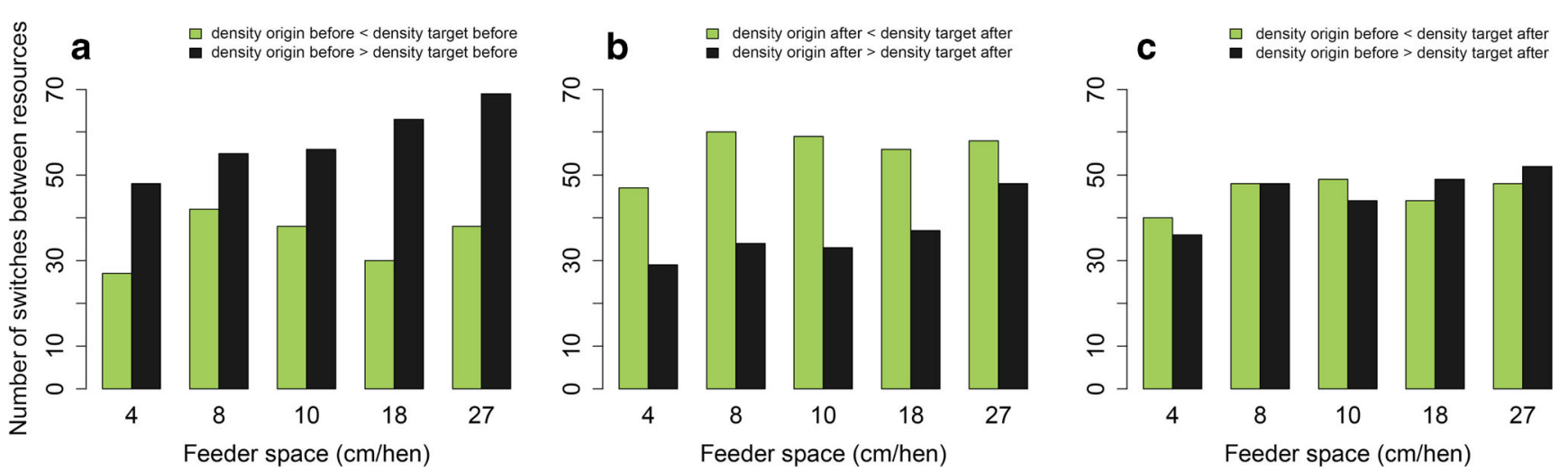

Fig. 4 Bird density at the resource of origin and target before and after the switch (a comparison of bird densities at the origin and target resource before the switch, $\mathbf{b}$ comparison of bird densities at the origin and target resource after the switch, $\mathbf{c}$ comparison of bird densities at the origin resource before the switch and target resource after the switch) 


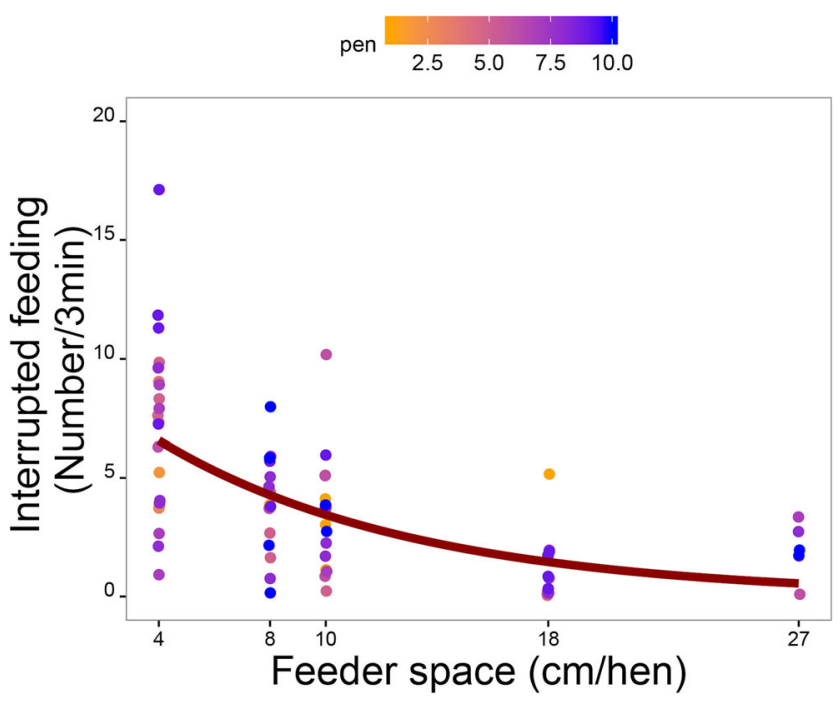

Fig. 5 Relationship between number of interrupted feeding events per 3min observation period ( $y$-axis) and feeder space ( $x$-axis). The dots represent raw data points and colors pens. Best fitted line is based on the generalized linear model without random factor. Sample size: $n=167$ replicates

patches may affect fitness in various ways. That is, disproportional settlement is not necessarily indicative of a break-down of the relation between animal distribution and fitness, but more likely an indicator for a breakdown of the linear relationship between resource availability and fitness. In the following we will, therefore, closely examine the mechanisms that are likely responsible for the deviations from the IFD both at the lower and upper end of resource abundance.

Observations at both ends of the resource spectrum suggest different mechanisms are at work. For small feeder spaces, increased aggression and increased disturbances of feeding activity (interrupted feeding) suggests that birds had to compete to access the feeder. For large overall feeder spaces, we observed low levels of aggression and disturbances, and hence, we speculate that the observed deviation from the IFD might be due to social attraction of animals rather than being driven by competition. Social attraction typically occurs in groups of chickens (Meunier-Salaün and Faure 1984) and was, in fact, already expected by Allee et al. (1949, discussed in Parker and Stuart 1976) as a cause for deviations from the IFD. However, social attraction may not be the only explanation for the deviation from the IFD at excessive feeder space allocations. Other potential factors are changes in food motivation and individual preferences for spatial locations or social partners. A longer time-window for behavioral observations across diurnal variations in motivation to feed and tracking of spatial locations and social partners at the feeders would allow disentangling their effects in future studies aimed to elucidate the mechanisms responsible for deviations from the IFD at excessive resource allocations.

Gathering sufficient information about resource quality is one of the most important prerequisites for establishing the IFD (Milinski 1984; Abrahams 1989; Korona 1990). The distribution of fish got closer to the "ideal free" when animals had more time to gather information, although the effect decreased with increasing aggression (Hakoyama and Iguchi 2001). Information can be gathered by sampling (e.g., individuals move between the resources) or observing from a distance. Animals may be sensitive to competitor densities, competitor activities, and/or levels of aggression at each resource location. In the current study, competitor density was more often lower at the target resource than at the original resource before a bird switched between the feeders suggesting that birds had a good perception of the differences in competitor distribution between the sites. Interestingly, the birds that moved from one source to another did not experience a change in density at the feeder, while those that stayed behind experienced a decrease in bird density. This might be a consequence of interrupted bird ratio between the feeders due to birds transitioning from being away of the feeder to accessing the feeder, as the frequency of transitions was $14 \times$ higher than the frequency of switches between the feeders. Aggression at the feeding sites might also be a cause for switching as it has been suggested that levels of aggression might indicate resource profitability (Kennedy and Gray 1994). However, empirical evidence for this assertion is lacking (Kennedy and Gray 1997; Koops and Abrahams 1999). Similar to Koops and Abrahams' (1999) results, we recorded equal levels of aggression at both resources in a pen (for all feeder spaces), hence, aggression was likely not used as an indicator of resource profitability or a reason for switching between feeding sites.

A secondary aim of this study was to investigate whether the IFD could serve as a yardstick to determine minimum requirements for housing conditions of group housed animals. By (i) assessing animal distributions over a sufficiently large range of the overall input (e.g., feeder space as in the current study) from scarce to abundant and (ii) combining it with a meaningful indicator of animal welfare (e.g., aggression and jostling as in the current study), we demonstrated that resource allocations below those that lead to IFD were associated with an escalation in aggression and jostling as birds tried to cope with the increased competition. This validation against accepted welfare indicators leads us to suggest that the IFD is a reliable indicator of how birds are experiencing different resource allocations and thus can be a useful tool to determine minimum resource allocations. Our findings suggest that a feeder space of between 8 and $10 \mathrm{~cm} /$ hen may be minimum that allows all birds access to the feeder when motivated to feed, without compromising their welfare by escalating aggression. Given the current differences between countries regarding minimum feed trough requirements, such information can be especially useful to legislators. Further, we suggest that an IFD approach could potentially be used to identify minimum allocations of other resources, not least because measuring competition at a resource is a labor-intensive task, while the distribution of animals between resources can be assessed automatically. 
Competition for resources and risk of predation are the main drivers for animal distributions, and the one dominating in a secure environment such as a commercial animal facility will likely depend on the abundance of resources. For most resources, the intensity of competition is density dependent and governed by the simple economic equation for supply and demand. We were, therefore, surprised to see that the vast majority of studies investigating animal distributions failed to vary both overall resource abundance and resource distribution over an adequately extensive range (Kennedy and Gray 1993). In doing so, we can see a pattern that fits well with the predictions of the IFD theory. Our findings also suggest that perceived mismatches of empirical data with model predictions (i.e., undermatching) in previous studies are well in line with our expectations and in support of the general applicability of the IFD models to animal distributions.

Supplementary Information The online version contains supplementary material available at https://doi.org/10.1007/s00265-020-02949-3.

Acknowledgments We thank Markus Schwab for helping set up the experiment and whenever questions arose, Elena Kirillova for the help in the barn, and Tomaž Toplak for writing a randomization-program and helping with the figures. Many thanks also to John McNamara for providing his opinion on the manuscript. Additionally, we kindly thank the anonymous reviewers whose suggestions helped improve and clarify this manuscript.

Authors' contributions JS, BV, LJK, HW, and MJT designed the study. JS conducted the experiment, collected, and analyzed the videos, performed the statistical analysis, and wrote the first draft of the paper. BV advised on the statistical analysis. All authors wrote the manuscript.

Funding The study was funded by the Swiss Federal Food Safety and Veterinary Office (Project number 2.13.10).

Data availability The datasets generated during and/or analyzed during the current study are available from the corresponding author on reasonable request.

\section{Compliance with ethical standards}

Competing interests The authors declare that they have no competing interests.

Ethical Approval The study was approved by the Cantonal Veterinary Office of Bern, Switzerland (Cantonal license number BE 85/13), and all corresponding ethical guidelines were followed.

Open Access This article is licensed under a Creative Commons Attribution 4.0 International License, which permits use, sharing, adaptation, distribution and reproduction in any medium or format, as long as you give appropriate credit to the original author(s) and the source, provide a link to the Creative Commons licence, and indicate if changes were made. The images or other third party material in this article are included in the article's Creative Commons licence, unless indicated otherwise in a credit line to the material. If material is not included in the article's Creative Commons licence and your intended use is not permitted by statutory regulation or exceeds the permitted use, you will need to obtain permission directly from the copyright holder. To view a copy of this licence, visit http://creativecommons.org/licenses/by/4.0/.

\section{References}

Abernethy KE, Allison EH, Molloy PP, Côté IM (2007) Why do fishers fish where they fish? Using the ideal free distribution to understand the behaviour of artisanal reef fishers. Can J Fish Aquat Sci 64: 1595-1604

Abrahams MV (1989) Foraging guppies and the ideal free distribution: the influence of information on patch choice. Ethology 82:116-126

Abrahams MV (1986) Patch choice under perceptual constraints: a cause for departures from an ideal free distribution. Behav Ecol Sociobiol 19:409-415

Allee WC, Park O, Emerson AE, Park T, Schmidt KP (1949) Principles of animal ecology. Saunders Company, Philadelphia, PA, USA

Banks EM, Wood-Gush DG, Hughes BO, Mankovich NJ (1979) Social rank and priority of access to resources in domestic fowl. Behav Process 4:197-209. https://doi.org/10.1016/0376-6357(79)90001-9

Bates D, Maechler M, Bolker B, Walker S (2015) Fitting linear mixedeffects models using \{lme4\}. J Stat Softw 67:1-48. https://doi.org/ 10.18637/jss.v067.i01

Bautista LM, Alonso JC, Alonso JA (1995) A field test of ideal free distribution in flock-feeding common cranes. J Anim Ecol 64: $747-757$

Beckmann JP, Berger J (2003) Using black bears to test ideal-free distribution models experimentally. J Mammal 84:594-606

Berec M, Křivan V, Berec L (2006) Asymmetric competition, body size, and foraging tactics: testing the ideal free distribution in two competing fish species. Evol Ecol Res 8:929-942

Bradbury JW, Vehrencamp SL, Clifton KE (2015) The ideal free antelope: foraging dispersions. Behav Ecol 26:1303-1313

Briese A, Spindler B (2013) Diskussion tierschutzrechtlicher Mindestsitzstangenlängen und Trogplatzbreiten anhand von biometrischen Daten zu Tierbreiten von LSL- und LBLegehennen. Berl Munch Tierarztl Wochenschr 126:163-168. https://doi.org/10.2376/0005-9366-126-163

Church KDW, Grant JWA (2019) Ideal despotic distributions in convict cichlids (Amatitlania nigrofasciata)? Effects of predation risk and personality on habitat preference. Behav Process 158:163-171

Cressman R, Křivan V, Garay J (2004) Ideal free distributions, evolutionary games, and population dynamics in multiple-species environments. Am Nat 164:473-489

Done E, Wheatley S, Mendl M (1996) Feeding pigs in troughs: a preliminary study of the distribution of individuals around depleting resources. Appl Anim Behav Sci 47:255-262. https://doi.org/10. 1016/0168-1591(95)00655-9

Febrer K, Jones TA, Donnelly CA, Dawkins MS (2006) Forced to crowd or choosing to cluster? Spatial distribution indicates social attraction in broiler chickens. Anim Behav 72:1291-1300. https://doi.org/10. 1016/j.anbehav.2006.03.019

Fretwell SD, Lucas HL (1969) On territorial behavior and other factors influencing habitat distribution in birds. Acta Biotheor 19:16-36

Gillis DM, Kramer DL (1987) Ideal interference distributions: population density and patch use by zebrafish. Anim Behav 35:1875-1882

Giovas CM, Fitzpatrick SM (2014) Prehistoric migration in the Caribbean: past perspectives, new models and the ideal free distribution of West Indian colonization. World Archaeol 46:569-589

Grant JWA, Gaboury CL, Levitt HL (2000) Competitor-to-resource ratio, a general formulation of operational sex ratio, as a predictor of competitive aggression in Japanese medaka (Pisces: Oryziidae). Behav Ecol 11:670-675

Hakoyama $\mathrm{H}$ (2003) The ideal free distribution when the resource is variable. Behav Ecol 14:109-115 
Hakoyama H, Iguchi K (2001) Transition from a random to an ideal free to an ideal despotic distribution: the effect of individual difference in growth. J Ethol 19:129-137

Harlander-Matauschek A, Beck P, Piepho H-P (2009) Taste aversion learning to eliminate feather pecking in laying hens, Gallus gallus domesticus. Anim Behav 78:485-490. https://doi.org/10.1016/j. anbehav.2009.05.020

Haugen TO, Winfield IJ, Vøllestad LA, Fletcher JM, James JB, Stenseth NC (2006) The ideal free pike: 50 years of fitness-maximizing dispersal in Windermere. Proc R Soc B 273:2917-2924

Houston AI, McNamara JM (1988) The ideal free distribution when competitive abilities differ: an approach based on statistical mechanics. Anim Behav 36:166-174. https://doi.org/10.1016/S00033472(88)80260-4

Jazwa CS, Kennett DJ, Winterhalder B (eds) (2013) California's Channel Islands: the archaeology of human-environment interactions. University of Utah Press, Salt Lake City

Kelly DW, Thompson CE (2000) Epidemiology and optimal foraging: modelling the ideal free distribution of insect vectors. Parasitology 120:319-327

Kennedy M, Gray RD (1993) Can ecological theory predict the distribution of foraging animals? A critical analysis of experiments on the Ideal Free Distribution. Oikos 68:158-166

Kennedy M, Gray RD (1994) Agonistic interactions and the distribution of foraging organisms: individual costs and social information. Ethology 96:155-165. https://doi.org/10.1111/j.1439-0310.1994.tb00891.x

Kennedy M, Gray RD (1997) Habitat choice, habitat matching and the effect of travel distance. Behaviour 134:905-920

Koops MA, Abrahams MV (1999) Assessing the ideal free distribution: do guppies use aggression as public information about patch quality? Ethology 105:737-746. https://doi.org/10.1046/j.1439-0310.1999. 00456.x

Korona R (1990) Travel costs and ideal free distribution of ovipositing female flour beetles, Tribolium confusum. Anim Behav 40:186-187

Křivan V, Cressman R, Schneider C (2008) The ideal free distribution: a review and synthesis of the game-theoretic perspective. Theor Popul Biol 73:403-425

Kuznetsova A, Brockhoff PB, Haubo Bojesen Christensen R (2016) lmerTest: tests in linear mixed effects models, https://cran.rproject.org $/$ package $=$ lmerTest

Lima SL, Dill LM (1990) Behavioral decisions made under the risk of predation: a review and prospectus. Can J Zool 68:619-640

Maszczyk P, Babkiewicz E, Czarnocka-Cieciura M, Gliwicz ZM, Uchmanski J, Urban P (2018) Ideal free distribution of Daphnia under predation risk - model predictions and experimental verification. J Plankton Res 40:471-485. https://doi.org/10.1093/plankt/fby024

McNickle GG, Brown JS (2014) An ideal free distribution explains the root production of plants that do not engage in a tragedy of the commons game. J Ecol 102:963-971

Menezes JFS, Kotler BP (2019) The generalized ideal free distribution model: merging current ideal free distribution models into a central framework. Ecol Model 397:47-54

Meunier-Salaün MC, Faure JM (1984) On the feeding and social behaviour of the laying hen. Appl Anim Behav Sci 13:129-141. https:// doi.org/10.1016/0168-1591(84)90058-3

Milinski M (1979) An evolutionarily stable feeding strategy in sticklebacks. Z Tierpsychol 51:36-40

Milinski M (1984) Competitive resource sharing: an experimental test of a learning rule for ESSs. Anim Behav 32:233-242
Milinski M (1994) Ideal free theory predicts more than only input matching: a critique of Kennedy and Gray's review. Oikos 71: 163-166. https://doi.org/10.2307/3546183

Milinski M, Heller R (1978) Influence of a predator on the optimal foraging behavour of sticklebacks (Gasterosteus aculeatus L.). Nature 275:642-644

Mills D, Faure JM (1989) Social attraction and the feeding behaviour of domestic hens. Behav Process 18:71-85. https://doi.org/10.1016/ S0376-6357(89)80006-3

Moritz M, Hamilton IM, Scholte P, Chen Y-J (2014) Ideal free distributions of mobile pastoralists in multiple seasonal grazing areas. Rangeland Ecol Manage 67:641-649

Munubi RN, McIntyre PB, Vadeboncoeur Y (2018) Do grazers respond to or control food quality? Cross-scale analysis of algivorous fish in littoral Lake Tanganyika. Oecologia 188:889-900. https://doi.org/ 10.1007/s00442-018-4240-1

Murali G, Kumari K, Kodandaramaiah U (2019) Dynamic colour change and the confusion effect against predation. Sci Rep 9:274. https:// doi.org/10.1038/s41598-018-36541-7

Parker GA (1978) Searching for mates. In: Krebs JR, Davis NB (eds) Behavioural ecology: an evolutionary approach, 1st edn. Blackwells, Oxford, pp 214-244

Parker GA, Stuart RA (1976) Animal behavior as a strategy optimizer: evolution of resource assessment strategies and optimal emigration thresholds. Am Nat 110:1055-1076

Parker GA, Sutherland WJ (1986) Ideal free distributions when individuals differ in competitive ability: phenotype-limited ideal free models. Anim Behav 34:1222-1242

R Core Team (2016) R: A language and environment for statistical computing. R Foundation for Statistical Computing, Vienna, Austria http://www.R-project.org

Sirovnik J, Würbel H, Toscano MJ (2018) Feeder space affects access to the feeder, aggression, and feed conversion in laying hens in an aviary system. Appl Anim Behav Sci 198:75-82

Sokal RR, Rohlf FJ (1995) Biometry, 3rd edn. WH Freeman and Co., New York

Sutherland WJ (1983) Aggregation and the 'ideal free' distribution. J Anim Ecol 52:821-828

The Council of the European Union (1999) Council Directive 1999/74/ EC of 19 July 1999 laying down minimum standards for the protection of laying hens, https://eur-lex.europa.eu/legal-content/EN/TXT/ HTML/?uri = CELEX:31999 L0074\&from $=$ EN

The Swiss Federal Council (2008) Minimum requirements for housing domestic animals. Swiss Animal Welfare Ordinance, https:/www. zuerchertierschutz.ch/fileadmin/user_upload/Tierschutzthemen/pdf/ Tierschutzverordnung_e.pdf

Tregenza T (1995) Building on the ideal free distribution. Adv Ecol Res 26:253-307

Tregenza T, Thompson DJ, Parker GA (1996) Interference and the ideal free distribution: oviposition in a parasitoid wasp. Behav Ecol 7: 387-394

United Egg Producers (2016) Animal Husbandry Guidelines for U.S. Egg Laying Flocks, https://uepcertified.com/wp-content/uploads/2019/ 09/CF-UEP-Guidelines 17-3.pdf

Zach R, Smith JNM (1981) Optimal foraging in wild birds. In: Kamil AC, Sargent TD (eds) Foraging behavior. Garland STPM Press, New York, pp 95-109

Publisher's note Springer Nature remains neutral with regard to jurisdictional claims in published maps and institutional affiliations. 